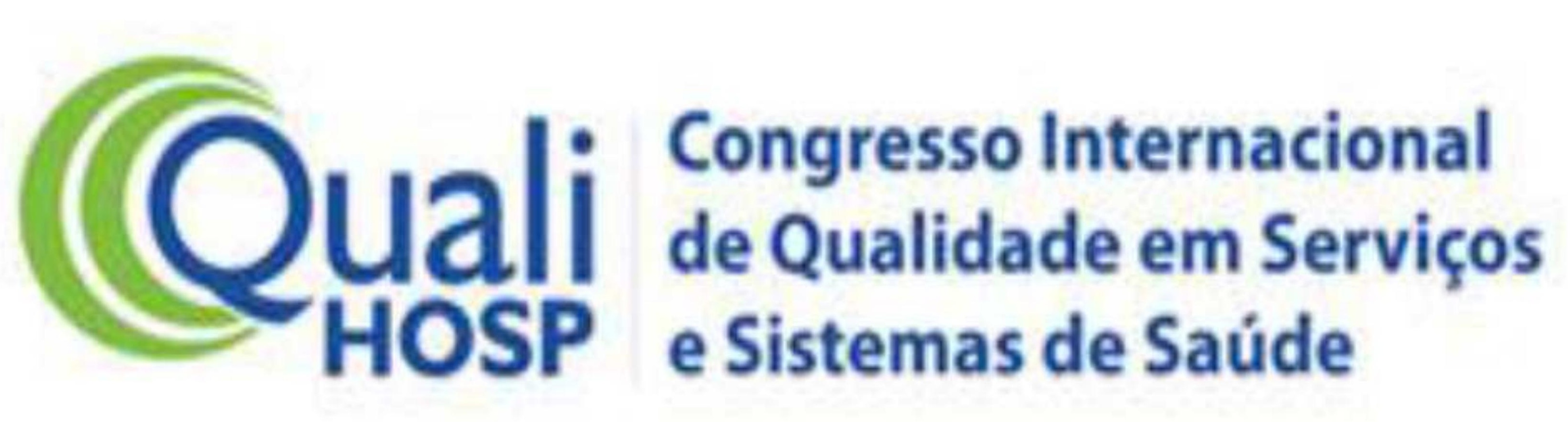

\title{
IMPACTO DA CLASSIFICAÇÃO DE ROBSON NA REDUÇÃO DA TAXA DE CESÁREAS EM UM HOSPITAL MUNICIPAL DE SÃO PAULO
}

\author{
Eixo temático :Avaliação e Qualidade do Cuidado
}

\begin{abstract}
Jussara Leiko Sato Tebet; Anamarya Rocha Vitorino; Thaissa Gomes Borralho; Mariana Salvalágio Nantes; Mirna J Cristina Dos Santos
\end{abstract}

\section{INTRODUÇÃO}

A OMS, Organização Mundial da Saúde, considera como ideal uma taxa de cesáreas ajustada para a população brasileira entre $25 \%$ e $30 \%$ de todos os partos. No Brasil, estima-se em $52 \%$ o total de cesáreas e, considerando apenas a rede privada, este número chega a $88 \%$ de mulheres que são submetidas, anualmente, a cesarianas(CS) sem indicação obstétrica. Esse aumento levou as Sociedades Médicas, juntamente com a OMS, a adotarem um sistema de classificação padrão para que possam ser feitas comparações e, a partir de então, sejam estabelecidas medidas para melhorar $o$ atendimento e reduzir a taxa de cesárea. A cesárea não é isenta de riscos, estando associada à maior morbi-mortalidade materna e infantil, quando comparada ao parto vaginal.

\section{OBJETIVO}

No presente estudo, buscamos observar os resultados da Classificação de Robson na maternidade municipal de São Paulo. Essa classificação baseia-se em: gestação única ou múltipla, paridade e presença de cesárea prévia, apresentação, forma de início ou cesariana antes do trabalho de parto, além de idade gestacional no parto.

\section{RESULTADO}

O grupo 1: $12,1 \%$ (intervalo, 4,5 - 20,3\%); O grupo 2: 20,9\% (intervalo, 11,1 - 27,3\%); O Grupo 3: 4,2\% (intervalo, 0 10\%);O grupo 4:10,6\%;O Grupo 5: $61,5 \%$ (intervalo $48 \%$ $78,6 \%$ ); O grupo 6: $73,6 \%$ (intervalo $50 \%-100 \%$ ); O grupo 7 : $73,3 \%$ (intervalo $33,3 \%-100 \%$ ); O grupo $8: 70,8 \%$ dos casos; O grupo 9: 100\%; O grupo 10 a média da taxa de CS foi de $31,2 \%$ (intervalo $15,4-57,1 \%$ ).

\section{DISCUSSÃO}

O serviço estudado apresentou uma taxa global de CS muito próxima ao esperado pelo Ministério da Saúde, $31 \%$ e isto foi resultante em grande parte ao uso da escala de Robson. A classificação Robson é uma ferramenta muito útil na redução das taxas de CS, revelando o perfil do serviço estudado, além de mensurar quais grupos mais contribuíram para as taxas de CS e dessa forma monitorizar e criar estratégias nestes grupos específicos afim de reduzir os índices do parto cesárea. Além disso, permite um feedback aos profissionais envolvidos estimulando a avaliação criteriosa das indicações de CS, bem como o incentivo na pesquisa em busca de aprimorar as técnicas de indução de parto e melhoria na condução do trabalho de parto.

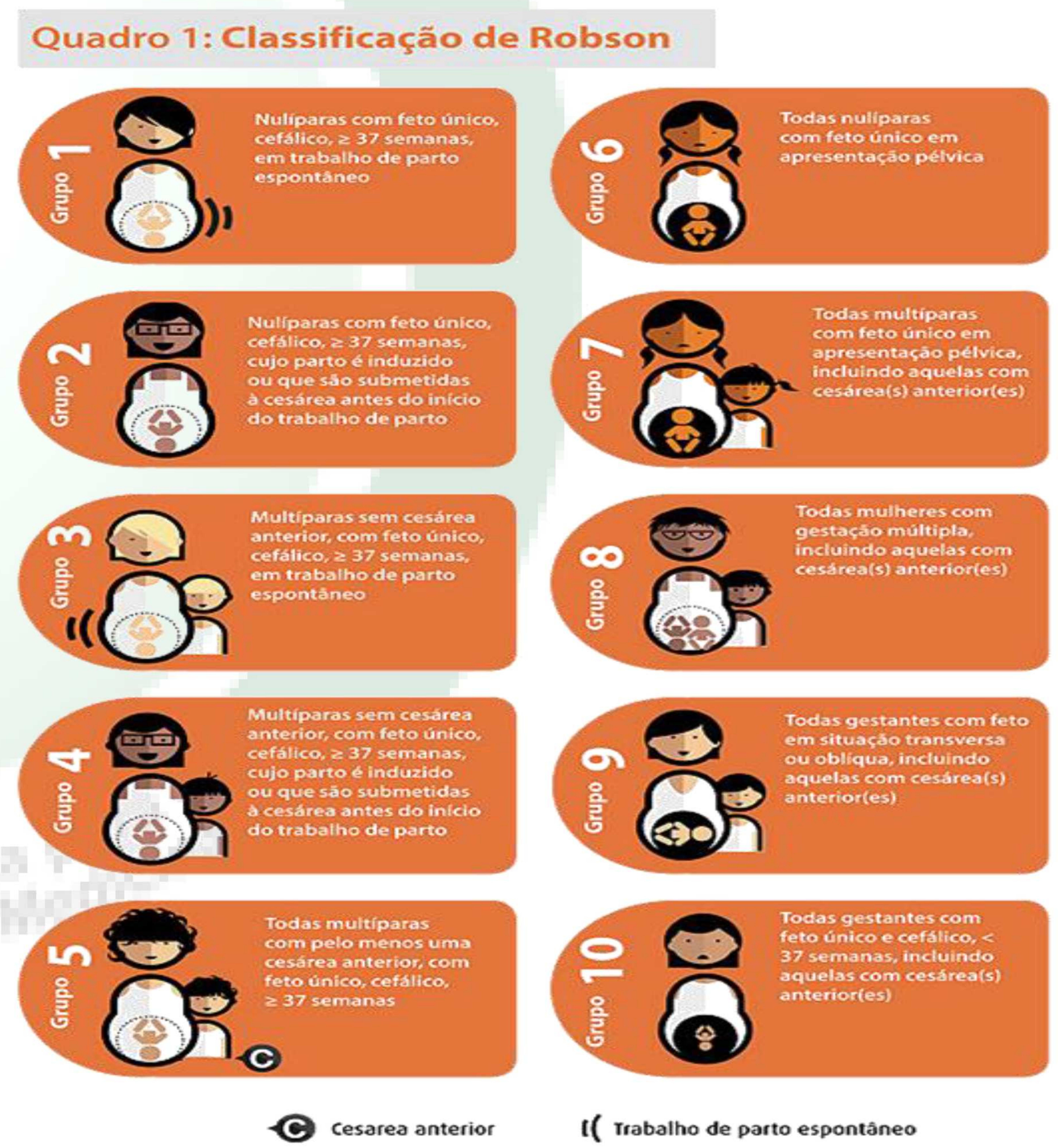

\section{REFERÊNCIA}

1. BETRÁN, A. P. et al. A Systematic Review of the Robson Classification for Caesarean Section: What Works, Doesn't Work and How to Improve It. PLoS ONE,v. 9, n. 6, p. e97769, 2014. 